\title{
RULES OF ORIGIN SEBAGAI INSTRUMEN PENANGANAN PRAKTIK ILLEGAL TRANSHIPMENT
}

\author{
ESTY HAYU DEWANTY R.K.
}

Pengamat Hukum, esty_hayu@yahoo.com

\begin{abstract}
The influence of globalization has become wider and it caused the increasing of intensity of world's trade between countries. However, this positive development is followed by a lot of fraudulent in international trading such as Illegal Transhipment, whereas a country exports to other countries through the third country by some methods. Indonesia, as an active member of international trade forums, is also threaten to be one of the victim of Illegal Transhipment, by the method of Certificate of Origin. If it's allowed, Indonesian's traders will suffer financial loss and also will interfere with national economic stabilization. Rules of Origin on the Certificate of Origin is one of indicator of Illegal Transhipment and can be used as the reference of trade's policy to give back national economic loss. Therefore, preventive and repressive handling of Illegal Transhipment through Rules of Origin is needed to be done.
\end{abstract}

Keywords : Rules of Origin, Certificate of Origin, Illegal Transhipmen

\begin{abstract}
Abstrak
Semakin meluasnya pengaruh globalisasi memicu meningkatnya intensitas perdagangan dunia antar negara. Namun, perkembangan positif ini juga diikuti dengan berbagai praktik kecurangan dalam perdagangan internasional seperti Illegal Transhipment, dimana suatu negara melakukan ekpor ke negara lain melalui negara ketiga dengan modus-modus tertentu. Indonesia sebagai salah satu peserta aktif dalam berbagai forum perdanganan internasional juga tidak luput dari ancaman Illegal Transhipment dengan modus penipuan Certificate of Origin. Jika dibiarkan, hal ini dapat merugikan produsen dalam negeri dan mengganggu stabilitas perekonomian nasional. Rules of Origin yang dituangkan dalam Certificate of Origin merupakan salah satu indikator terjadinya Illegal Transhipment dan dapat digunakan sebagai acuan untuk mengenakan kebijakan perdagangan untuk mengembalikan kerugian nasional. Oleh sebab itu, penanganan Illegal Transhipment melalui Rules of Origin baik secara preventif maupun represif harus dilakukan.
\end{abstract}

Kata Kunci : Rules of Origin, Certificate of Origin, Illegal Transhipmen

\section{Pendahuluan}

Semakin liberalnya perdagangan antar negara, praktik dagang yang terjadi sering menimbulkan peluang terjadinya praktik dagang tidak sehat. Salah satu dari praktik penyimpangan tersebutadalah adanyaillegal transhipment yang dapat mengakibatkan 
kerugian atau injury bagi dunia industri dalam negeri.

Tindakan illegal transhipment menjadi isu hangat setelahterjadinya krisis finansial di Amerika Serikat dimana terjadi peningkatan ekspor di beberapa negara. ${ }^{1}$ Peningkatan ekpor tersebut selain dimaksudkan sebagai bentuk pengalihan ekspor juga sebagai antisipasi menambah likuiditas keuangan masing-masing negara. ${ }^{2}$ Upaya menggenjot ekpor tersebut biasa dilakukan dengan melakukan strategi dumping ke pasar-pasar potensial termasuk Indonesia. Akibatnya barang-barang tersebut akan dikenakan anti-dumping maupun safeguard sebagai bentuk perlindungan bagi produsen di negara tujuan ekspor.

Suatu Negara yang dikenakan kebijakan anti-dumping ataupun safeguard dari Negara lain berpotensi melakukan cara-cara yang bertentangan dengan prinsip GATT/ WTO demi memaksimalkan ekspor dan keuntungan. Penyebabnya adalah barang yang dikenakan anti-dumping ataupun safeguard tidak lagi kompetitif di pasar tujuan ekspor karena pengenaan bea masuk yang tinggi. Sehingga mereka melakukan pemindahkapalan atau illegal transhipment dengan modus pemalsuan dokumen Certificate of Origin. ${ }^{3}$

Salah satu kasus yang melibatkan nama Indonesia adalah tuduhan penipuan ekspor tekstil dengan modus illegal transhipment. ${ }^{4}$

\footnotetext{
1 Warta Bea Cukai. Krisis Ekonomi Global Picu Lonjakan Inisiasi Dumping. Edisi 418. September 2009.

2 Rdar, "Depdag Perketat Impor Barang," www. rdar.wordpress.com, diakses pada 2 April 2011.

3 Ibid.

4 "Pemerintah Waspadai Tuduhan Ekspor Sepatu ke Brazil", www.tempointeraktif.com, edisi Selasa 7
}

AS mengkonsumsi sekitar $30 \%$ dari total ekspor tekstil di dunia, sehingga AS merupakan salah satu pasar yang potensial. Dalam salah satu kebijakannya, AS menerapkan pembatasan kuota pada ekspor garmen dari China sejak tahun 2005 melalui mekanisme safeguard yang dinyatakan sah oleh WTO. Mekanisme ini bertujuan melindungi produsen domestik AS yang mengalami kerugian akibat serbuan produk impor China dengan harga yang kompetitif.

Namun sejak kebijakan tersebut diterapkan, Instansi kepabeanan AS mencatat adanya ekspor produk dari Indonesia ke AS yang meningkat secara signifikan. Dalam 11 bulan terakhir di tahun 2005, ekspor Indonesia meningkat $17,4 \%$ senilai $\$ 2.9$ juta. Hal ini menimbulkan kecurigaan AS dan menuduh Indonesia melakukan Illegal transhipment. 5

Setelah dilakukan penyelidikan, ditemukan fakta bahwa illegal transhipment yang dilakukan China terhadap produk Indonesia tersebut dilakukan karena sangat mudah untuk melakukan pemalsuan $\mathrm{COO}$ di Indonesia. Tekstil dan garmen dari China sering dikirim ke Indonesia melalui Singapura atau Hongkong untuk dilakukan transhipment menggunakan dokumen $\mathrm{COO}$ palsu.

Kasus lain yang terjadi adalah masuknya ban asal China dan India yang masuk ke Indonesia melalui praktek pemalsuan dokumen Certificate of Origin atau Surat Keterangan Asal. Certificate of

September 2010, diakses pada 25 Mei 2011.

5 Ibid. 
Origin ban dipalsukan sehingga seolah-olah produk tersebut berasal dari negara anggota ASEAN termasuk Indonesia. ${ }^{6}$

Sebaliknya, China dan India menggunakan nama Indonesia untuk masuk ke pasar Negara ASEAN lainnya dalam lingkup preferensi tarif ASEAN Free Trade Area. Tindakan ini diikuti dengan melakukan pemalsuan sertifikat asal dari negara lain dengan tujuan untuk menghindarkan bea masuk yang tinggi. Sebagai perbandingan bea masuk produk ban antar anggota ASEAN adalah 5 (lima) persen, sedangkan bea masuk ban bagi produk di luar anggota adalah sebesar 15 (lima belas) persen.

Tindakan pemalsuan Certificate of Origin inilah yang dikenal dengan circumvention yang bertujuan untuk menghindari bea masuk yang besar serta didorong oleh kondisi domestik dimana produsen ban mereka mengalami kelebihan stok karena melemahnya permintaan domestik. Sehingga mereka terdorong untuk melakukan illegal transhipment ke Indonesia karena kebutuhan ban di pasar ritel Indonesia cukup besar yakni sekitar 5 (lima juta) per tahun. ${ }^{7}$

Untuk mengatasi kasus di atas, Negara maju seperti AS dan Uni Eropa meggunakan instrumen Rules of Origin untuk melindungi konsumen terhadap perbuatan curang atau indikasi yang menyesatkan. Hal ini karena konsumen dimanapun memiliki hak untuk mengetahui dimana barang itu dibuat yang

\footnotetext{
6 Nurmayanti, "Ban Asal China dan India Makin Marak," www.tractor-truck.com, diakses pada 3 April 2011. Ibid.
}

merupakan hak bagi konsumen untuk menentukan keputusan membeli suatu barang (ultimate purchaser). ${ }^{8}$ Selain itu, adanya proses produksi yang dilakukan lebih dari satu Negara dan melibatkan komponen-komponen dari berbagai Negara lainnya menyebabkan tidak ada suatu barang pun yang benar - benar diproduksi oleh country of originnya sehingga Rules of Origin dipandang sebagai cara perlindungan yang paling efektif. ${ }^{9}$

Dari penjelasan latar belakang permasalahan di atas, maka Penulis menarik rumusan masalah sebagai berikut:

1. Pengaturan Rules of Origin dalam perjanjian internasional dan implementasinya dalam UndangUndang Nomor 10 Tahun 1995 jo Undang-Undang Nomor 17 Tahun 2006 tentang Kepabeanan.

2. Fungsi Rules of Origin sebagai Instrumen Penanganan praktik illegal transhipment dalam kerangka perdagangan internasional

\section{Konsep Rules of Origin}

Rules of Origin adalah kriteria yang digunakan untuk menentukan asal negara suatu barang. Hal ini penting karena dalam perdagangan internasional, kewajiban dan pembatasan dalam beberapa kasus tergantung pada sumber impor suatu

\footnotetext{
8 Raj Bhala,2, "International Trade Law Theory and Practice," (New York : Lexis Publishing, 2001), hal. 459.

9 LaNasa, Joseph A., "An Evaluation of the Uses and Importances of Rules of Origin, and the Effectiveness of the Uruguay Round's Agreement on Rules of Origin in Harmonizing and Regulating Them.", 1995, www. centers.law.nyu.edu, diakses pada 3 Maret 2011.
} 
barang. ${ }^{10}$ Rules of Origin ini dituangkan dalam bentuk Certificate of Origin atau Surat Keterangan Asal (SKA) sebagai dokumen yang menunjukkan bahwa suatu barang telah memenuhi Ketentuan Asal Barang dan sekaligus berhak memperoleh preferensi tarif.

Dalam kelengkapan dokumen impor, pembuktian barang/komoditi ditunjukkan dengan adanya penerbitan Surat Keterangan Asal dari negara asal/produsen untuk penyelesaian dokumen pabean yang merupakan hal mutlak untuk untuk diverifikasi dalam pengeluaran barang dari Negara lain sesuai dengan prosedur dan ketentuan yang berlaku. ${ }^{11}$

Menurut WTO, tujuan dari penerapan Rules of Origin adalah ${ }^{12}$ :

(1) sebagai ukuran untuk menerapkan tindakan dan instrumen kebijakan perdagangan seperti anti-dumping dan safeguard;

(2) untuk memutuskan apakah suatu produk impor akan dikenai Most Favoured Nation (MFN) atau tindakan preferensi;

(3) untuk keperluan statistik perdagangan;

(4) untuk keperluan aplikasi pelabelan dan persyaratan marking; dan

(5) untuk keperluan goverment procurement.

Tujuan lainnya adalah sebagai filter instrument dari illegal transhipment dan penolakan pembayaran bea masuk. Barang

\footnotetext{
10 www.wto.org, diakses padal 12 Maret 2011

Ibid.

12 www.wto.org, diakses pada 2 Mei 2011.
}

atau produk yang terkena anti-dumping, countervailing measures dan tindakan safeguard menjadi tidak kompetitif akibat dikenakan bea masuk yang tinggi sehingga sering sekali beberapa eksportir melakukan illegal transhipment untuk mengelabui asal usul barang.

\section{Pengaturan Rules of Origin Dalam Perjanjian Internasional}

GATT mendefinisikan Rules of Origin sebagai undang-undang, peraturan, dan ketentuan administratif yang ditetapkan oleh setiap Negara anggota untuk menentukan Negara asal barang, sepanjang ketentuan asal barang tersebut tidak berkaitan dengan "contractual or autonomous trade leading to the granting of tariff preferences" yang dilaksanakan di luarpasal I : 1 GATT. ${ }^{13}$ Selain itu, ketentuan mengenai prisip-prinsip Rules of Origin diatur dalam article IX GATT yang masih bersifat umum dan berfungsi sebagai pedoman sampai terbentuk sistem harmonisasi Rules of Origin.

Pengaturan lain yang lebih rinci terdapat dalam Bab I Annex K dari Kyoto Convention, sebagai berikut :

1. Country of Origin adalah Negara dimana barang tersebut dihasilkan atau dibuat, sesuai dengan kriteria yang ditetapkan untuk keperluan penerapan tariff Pabean, pembatasan jumlah atau tindakan lain yang berkaitan dengan perdagangan.

2. Rules of Origin adalah ketentuan

13 Pasal 1 Agreement on Rules of Origin, Marrakesh Protocol to the General Agreement on Tariffs and Trade 1994, disahkan tanggal 15 April 1994 di Marrakesh, Maroko. 
khusus, yang dikembangkan dari prinsip - prinsip yang ditetapkan oleh Peraturan Perundang - undangan nasionalataukesepakataninternasional (mengenai "kriteria asal") yang ditetapkan oleh suatu Negara untuk menentukan asal barang.

3. Substantial Transformation adalah kriteria yang digunakan untuk menentukan asal barang dengan cara menganggapbahwaNegaraasalbarang adalah Negara dimana pengerjaan atau pengolahan substansial terakhir telah dilakukan, yang dianggap cukup memberikan sifat utama barang.

Selain itu, dalam Konvensi Kyoto juga mengatur mengenai prinsip - prinsip pelaksanaan Rules of Origin. Pertama, prinsip yang menentukan bahwa ketentuan asal barang bagi pelaksanaan tindakantindakan yang wewenang penerapannya di bidang impor dan ekspor dibebankan kepada Instansi Pabean, harus dibuat sesuai ketentuan-ketentuan dalam bab ini dan diterapkan berdasarkan ketentuan yang terdapat dalam Annex Umum. Kedua, prinsip yang menentukan bahwa barangbarang yang seluruhnya dihasilkan di Negara tertentu harus dianggap berasal dari Negara itu.

Pengaturan Rules of Origin dalam Undang-Undang Nomor 10 Tahun 1995 jo Undang-Undang Nomor 17 Tahun 2006 tentang Kepabeanan

Undang-Undang Nomor 10 Tahun 1995 jo Undang-Undang Nomor 17 Tahun
2006 tentang Kepabeanan atau selanjutnya disebut UU Kepabeanan ${ }^{14}$, lebih banyak mengadopsi perjanjian multilateral dalam GATT maupun WTO.

Pasal 1 ayat 7 membahas tentang definisi Pemberitahuan Pabean yakni sebagai berikut :

"pernyataan yang dibuat oleh orang dalam rangka melaksanakan kewajiban Pabean dalam bentuk dan syarat yang ditetapkan dalam UU Kepabeanan.”

Selanjutnya pasal 10 menyatakan bahwa :

"barang yang diekspor wajib diberitahukan menggunakan Pemberitahuan Pabean."

UU Kepabeanan tidak membahas definisi dan pengaturan mengenai Rules of Origin secara eksplisit. Pasal 3 dan 4 mengenai pemeriksaan pabean terhadap barang ekspor dan impor dapat diinterpretasikan sebagai pemeriksaan terhadap keabsahan COO termasuk di dalamnya kebenaran asal barang (Rules of Origin).

Penggunaan istilah Rules of Origin yang dalam praktik perdagangan internasional dinyatakan dalam COO, disebutkan sebagai pemberitahuan pabean dalam UU Kepabeanan. Penggunaan istilah pemberitahuan kepabeanan sebenarnya

${ }^{14}$ Undang-undang Nomor 10 Tahun 1995 tentang Kepabeanan (Lembaran Negara Tahun 1995 Nomor 75, Tambahan Lembaran Negara Tahun 1995 Nomor 3612) sebagaimana telah diubah dengan Undang-Undang Nomor 17 Tahun 2006 (Lembaran Negara Republik Indonesia Tahun 2006 Nomor 93, Tambahan Lembaran Negara Republik Indonesia Nomor 4661). 
kurang sesuai karena definisnya adalah seluruh dokumen yang menyangkut keperluan ekspor impor. Sedangkan COO merupakan jenis dokumen tertentu yang diwajibkan bagi pelaksanaan Free Trade Agreement.

Ketentuan Rules of Origin Indonesia lebih bersifat umum dan fleksibel. Suatu barang dapat disebut berasal dari Indonesia apabila :

1. telah mengalami pengerjaan atau pengolahan yang cukup dan mengubah bentuk, sifat, atau kegunaan dari bahan baku dasar yang dipergunakan dalam proses produksi;

2. memenuhi persyaratan kriteria proses (change in tariff headings) atau kriteria prosentase (value added).

Namun, tidak disebutkan berapa prosentase yang dikehendaki Indonesia untuk barang atau material non-original yang masuk ke wilayahnya. Sebagaimana dijabarkan dalam bab penentuan substantial transformation, apabila suatu negara menggunakan kriteria value-added maka suatu barang yang dihasilkan dari negara tersebut jika memiliki kandungan impor harus dinyatakan jumlah prosentasenya dalam COO sesuai kriteria dari negara tujuan ekspor.

\section{Konsep Illegal Transhipment}

Dalam Specific Annex E Revised Kyoto Convention 1999, disebutkan bahwa definisi transhipment adalah ${ }^{15}$ :

${ }^{15}$ Chapter 2 The International Convention on Simplification and Harmonization of Customs Procedures. "the Customs procedure under which goods are transferred under Customs control from the importing means of transport to the exporting means of transport within the area of one Customs office which is the office of both importation and exportation.

Sedangkan dalam kegiatan ekspor impor, definisi transhipment adalah "Transshipment is the act of shipping goods to an intermediate destination prior to reaching their ultimate end-use. Transshipment is a common practice with logistic benefits, but can be used to illegitimately to disguise country of origin or intent of the goods. ${ }^{16}$ " Jadi ketika suatu transhipment dilakukan dengan memalsukan dokumen asal barang atau komposisi barang maka dikategorikan sebagai illegal transhipment.

Sedangkan dalam ketentuan nasional, definisi tentang illegal transhipment tercantum secara tersurat dalam pasal 102 UU Kepabeanan sebagai tindakan penyelundupan. Secara harfiah, arti kata transhipment adalah to tranship atau dalam bahasaIndonesiadisebutpemindahkapalan. ${ }^{17}$ SementaradalamUUKepabeanandisebutkan sebagai penyelundupan. Perbedaan kata ini perlu dilakukan penyelarasan karena pada dasarnya kedua kata tersebut memiliki makna yang berbeda.

Sedangkan praktik pemalsuan dokumen COO sebagai modus illegal transhipment

16 "What is Transhipment?", Informed Trade International Import/Export, www.itintl.com, diakses pada 15 Maret 2011.

${ }^{17}$ Alan M. Steven dan Ed. Schmidgall Tellings, "Kamus lengkap Indonesia-Inggris", www.books.google. co.id, diakses pada 15 Maret 2011. 
diatur dalam pasal 103 dengan sanksi pidana penjara dan denda administrasi. Adapun norma dalam pasal 102 menetapkan tindakan yang dianggap sebagai penyelundupan, yaitu :

i. mengangkut barang impor yang tidak tercantum dalam manifes sebagaimana dimaksud dalam Pasal $7 \mathrm{~A}$ ayat (2);

ii. membongkar barang impor di luar kawasan pabean atau tempat lain tanpa izin kepala kantor pabean;

iii. membongkar barang impor yang tidak tercantum dalam pemberitahuan pabean sebagaimana dimaksud dalam Pasal 7A ayat (3);

iv. membongkar atau menimbun barang impor yang masih dalam pengawasan pabean di tempat selain tempat tujuan yang ditentukan dan/ atau diizinkan;

v. menyembunyikan barang impor secara melawan hukum;

vi. mengeluarkan barang impor yang belum diselesaikan kewajiban pabeannya dari kawasan pabean atau dari tempat penimbunan berikat atau daritempatlaindibawah pengawasan pabean tanpa persetujuan pejabat bea dan cukai yang mengakibatkan tidak terpenuhinya pungutan negara berdasarkan undang-undang ini;

vii. mengangkut barang impor dari tempat penimbunan sementara atau tempat penimbunan berikat yang tidak sampai ke kantor pabean tujuan dan tidak dapat membuktikan bahwa hal tersebut di luar kemampuannya; atau

viii. dengan sengaja memberitahukan jenis dan/atau jumlah barang impor dalam pemberitahuan pabean secara salah.

\section{Mekanisme dan Indikasi Praktik Illegal Transhipment}

Pada dasarnya praktik transhipment dalam perdagangan internasional diperbolehkan, sepanjang muatan atau barang yang dipindahkan sudah keluar dari wilayah kepabean negara transit atau sudah melalui Custom Clearance. ${ }^{18}$

Hal ini senada dengan pernyataan Menteri Perdagangan, Marie Elka Pangestu, yang menjelaskan bahwa tidak semua transhipment adalah ilegal. Mari Elka Pangestu juga mencontohkan impor Iran ke Indonesia biasanya melewati Abu Dhabi. Transhipment semacam ini merupakan hal yang normal. Namun, transhipment tersebut menjadi tidak normal ketika Cina mengimpor ke Amerika lewat Indonesia dengan alasan produknya dibatasi masuk ke Amerika. Kasus yang sama terjadi pada udang dan garmen dengan menggunakan surat keterangan asal (SKA) yang dipalsukan. ${ }^{19}$

Apabila muatan atau barang dari suatu negara, misalnya dari China, telah berada di wilayah kepabeanan negara transit, lalu diterbitkan atau dimohonkan Surat

18 "Verifikasi SKA Cegah Praktek Illegal Transhipment," www.bumn.go.id, diakses pada 15 Juni 2011.

19 Widiyanti, Arin, "Circumvention yang Perlu Diwaspadai, Bukan Transhipment", www.finance.detik. com, diakses pada 23 Juni 2011. 
Keterangan Asal atau COO dengan dokumen pendukung dari negara lain yang diragukan keabsahannya, misalnyamenggunakan $\mathrm{COO}$ dari Indonesia. Kemudian barang tersebut diekspor ke negara tujuan ekspor Amerika Serikat, maka hal ini tidak diperbolehkan karena termasuk illegal transhipment. ${ }^{20}$

Illegal transhipment bisa terjadi pada semua komoditi perdagangan. Namun umumnya praktek ini sering terjadi pada komoditas TPT (tekstil dan produk tekstil), udang, sepatu, alas kaki, kopi, dan barang elektronik.

Adapun indikasi suatu negara yang mungkin melakukan tindakan illegal transhipment adalah sebagai berikut ${ }^{21}$ :

1. Negara tersebut sedang dikenakan tindakan safeguard ${ }^{22}$

2. Negara tersebut sedang dikenakan tuduhan dumping ${ }^{23}$

3. Negara tersebut sedang dicurigai melakukan circumvention atau pengalihan tujuan ekspor.

Berdasarkan praktik yang terjadi, tujuan dari transhipment yang illegal ini adalah ${ }^{24}$ :

1. untuk menghindari pembebanan bea

${ }^{20}$ Ibid.

${ }^{21}$ Ibid.

${ }^{22}$ Dalam Agreement on Implementation of Article IV GATT atau dikenal dengan Anti-Dumping Agreement, yang dimaksud dengan dumping adalah suatu keadaan dimana barang-baranng yang dieskpor oleh suatu negara ke negara lain dengan harga yang lebih rendah dari harga jual di dalam negerinya sendiri atau nilai normal dari barang tersebut.

${ }^{23}$ Dalam Agreement on Safeguards GATT 1947, safeguard adalah tindakan pengamanan yang memiliki tujuan untuk melindungi industri dalam negeri dari lonjakan barang-barang impor yang merugikan atau mengancam industri di dalam negeri.

24 "Verifikasi SKA Cegah Praktek Illegal Transhipment," loc.cit. impor tinggi yang dikenakan pada negara - negara tertentu;

2. menghindari pembatasan impor termasuk pembatasan visa dan kuota;

3. untuk memanfaatkan free trade agreement yang menggunakan skema penurunan tariff yang rendah.

\section{Upaya Penanganan Illegal Transhipment di Indonesia}

Sejauh ini sanksi yang dikenakan Kementerian Perdagangan adalah pencabutan ijin perusahaan yang terbukti melakukan illegal transhipment. Untuk perusahaan yang melakukan impor dan memiliki lisensi impor, maka Kementerian Perdagangan akan mencabut lisensinya. Jika perusahaan yang bersangkutan hanya melakukan ekspor, maka Pemerintah hanya dapat meninjau izin SIUP dan Izin Usaha yang bersangkutan.

Dalam UU Kepabeanan, pelaku illegal transhipment akan dikenakan pasal 102 atas tindakan penyelundupan, dan dikenakan pidana penjara paling singkat 1 (satu) tahun dan pidana penjara paling lama 10 (sepuluh) tahun dan pidana denda paling sedikit Rp50.000.000,00 (lima puluh juta rupiah) dan paling banyak Rp5.000.000.000,00 (lima miliar rupiah). Selain itu, untuk modus illegaltranshipment dengan pemalsuan $\mathrm{COO}$ dikenakan pidana sebagaimana tercantum dalam pasal 103 UU Kepabeanan.

Sebagai bahan perbandingan, upaya represif penanggulangan illegal transhipment di AS tidak saja dilakukan dengan pencabutan ijin, tetapi juga 
pencabutan hak-hak istimewa importir, penyitaan barang impor dan pengenaan denda atas kerugian yang diderita AS akibat tindakan pemindahan kapalan tersebut. ${ }^{25}$

\section{Fungsi Rules of Origin Sebagai Instrumen Penanganan Praktik Illegal Transhipment}

\section{Rules of Origin Sebagai Instrument Penanganan Preventif}

\section{Rules of Origin sebagai Filter Instrument}

Keberadaan sistem anti - dumping sering mendapat tekanan dari kalangan eksportir maupun importir yang paling merasakan dampak dari tuduhan dumping. Keberatan utama yang dikemukakan adalah berlarut - larutnya keputusan untuk menentukan apakah produk - produk kertas tersebut diekspor dengan harga dumping dan apakah kegiatan dumping tersebut telah mengakibatkan 'material injury' terhadap industri lokal.

${ }^{25}$ Penalties : In addition to the loss of import privileges and seizure of imported merchandise, importers practicing transhipment may also be subject to an array of civil penalties under 19 U.S.C. 1592. Maximum penalties for transhipment are :

- Fraud: an amount not exceeding the domestic value of the merchandise.

- Gross Negligence : The lesser of

- the domestic value of merchandise, or

- four times the lawful duties, taxes, and fees, or

- if the violationdidnot affect the assessment of duties, 40 percent of dutiable value of the merchandise.

Negligence : The lesser of

- the domestic value of the merchandise.

- two times the lawful duties, taxes, and fees, or

- if the violationdid not affect the assessment of duties, 20 percent of dutiable value of the merchandise.
Sedangkan dalam kasus illegal transhipment, modus terjadinya tindakan tersebut adalah penyalahgunaan Certificate of Origin atau Surat Keterangan Asal (SKA). Maka kunci penegakkan dan pemberantasan illegal transhipment ini harus diawali dari SKA sebagai titik awal pelaku melakukan kecurangannya.

Ketentuan Asal Barang yang terdapat dalam dokumen Certificate of Origin dinilai sebagai suatu pemecahan masalah yang tepat untuk menangkal adanya unfair trade karena proses pemeriksaan dan konfirmasi keakuratan dokumen dapat dilakukan dengan cepat dan efisien. Keberadaan ROO sebagai filter instrument sangatlah menguntungkan kedua pihak baik importer maupun eksportir.

Adapun wujud dari eksistensi ROO sebgai filter instrument adalah sebagai berikut :

\section{- Verifikasi Rules of Origin}

Pemberian pembebasan bea masuk atau penerapan tarif preferensi sudah tentu memerlukan pengawasan yang ketat. Baik pihak partner perjanjian maupun Indonesia telah menyepakati apa yang disebut dengan prosedur Verifikasi Rules of Origin melalui dokumen $\mathrm{COO}$ atau lebih dikenal dengan Verifikasi Surat Keterangan Asal (SKA). Verifikasi ini merupakan proses penyelidikan aspek keabsahan SKAmulai dari pengecekan keabsahan dokumen, kebenaran pengisian SKA, dan atau kebenaran asal barang yang dilakukan atas permintaan di negara tujuan ekspor barang. ${ }^{26}$

${ }^{6}$ Surat Edaran Direktur Jenderal Bea dan Cukai Nomor SE-05/BC/2010 tentang Petunjuk Pelaksanaan 


\section{Pengecekan Keabsahan Dokumen}

Keabsahan dokumen meliputi keaslian dokumen SKA dan memastikan tanda tangan pejabat penanda tangan SKA. Keaslian dokumen meliputi ukuran kertas dan format SKA yang tidak sesuai dengan ketentuan sebagaimana dimaksud pada keterangan SKA. Sedangan tanda tangan SKA harus dilakukan oleh pejabat yang berwenang dari negara asal barang yang bersangkutan dan diberi cap jabatan.

\section{Kebenaran Pengisian SKA}

Masalah yang sering timbul terkait hal ini adalah tidak dicantumkannya nilai FOB dalam dokumen SKA dan deskripsi barang yang tidak sesuai dengan no. Kode barang.

3. Kebenaran Asal Barang (Rules of Origin)

Asal barang harus dipastikan apakah memenuhi ketentuan asal barang di negara tujuan ekspor atau tidak. Selain itu barang yang tercantum dalam dokumen harus merupakan barang yang tercakup dalam perjanjian Free Trade Agreement. Petugas dapat meragukan kebenaran Rules of Origin jika memiliki bukti nyata misalnya informasi tertulis yang telah diyakini kebenarannya seperti : informasi dari instansi pemerintah di dalam/luar negeri, hasil pemeriksaan intelijen Direktorat Jenderal Bea Cukai, dan hasil pemeriksaan pembukuan

Penelitan Dokumen Pemberitahuan Impor Barang Dalam rangka Skema Free Trade Agreement.
(2) Mekanisme Retroactive Check dan Verification Visit

Jika terdapat keraguan atau ketidak absahan dari form SKA, maka hal pertama yang dilakukan Petugas Peneliti Dokumen adalah melakukan Retroactive Check. Ini merupakan prosedur permintaan informasi oleh Negara Pengimpor tentang keabsahan SKA dan pemenuhan kriteria Ketentuan Asal Barang dari negara pengekspor dengan tujuan untuk memastikan agar barang yang diimpor berhak memperoleh tarif preferensi. ${ }^{27}$

Sedangkan Verification Visit adalah pelaksanaan verifikasi atas barang impor dalam skema Free Trade Agreement dengan mengadakan kunjungan ke negara pengekspor apabila hasil dari retroactive check dianggap tidak memuaskan. Karena sifatnya adalah pemeriksaan kunjungan lintas batas tentunya banyak prosedur yang harus dilalui oleh Petugas Peneliti Dokumen. ${ }^{28}$

\section{(3) Pengawasan Instansi Penerbit COO}

Seiring makin meningkatnya penggunaan $\mathrm{COO}$, maka kecenderungan penyalahgunaan $\mathrm{COO}$ juga semakin meningkat sehingga salah satu upaya yang dilakukan Pemerintah adalah dengan melakukan penambahan jumlah instansi Penerbit COO di Indonesia.

Departemen Perdagangan telah menerapkan kebijakan untuk mengurangi jumlah instansi penerbit COO demi menghindari adanya illegal transhipment

\footnotetext{
27 Ibid.

28 Ibid.
} 
yang mengancam produsen lokal. Adanya pemangkasan jumlah instansi penerbit menyebabkan pemeriksaan dan pengawasan COO lebih mudah dan terkoordinasi sehingga dapat mempersempit celah pelaku pelabelan ulang pada barang yang akan diekspor.

\section{- Penetapan Regional Content Value \\ Minimum}

Berdasarkan skema CEPT-AFTA dimana Indonesia tergabung di dalamnya, diterapkan adanya Regional Content Value (RVC) sebesar 40\%. Regional Content Value adalah "requiring the product either to acquire a minimum percentage of local value added in the exporting country or not to exceed a maximum percentage of foreign (non-originating) materials." ${ }^{29}$ Jadi penggunaan RVC sebesar $40 \%$ maksudnya yaitu jika seluruhnya mengandung materi dari suatu negara anggota atau paling sedikit $40 \%$ kandungan materi berasal dari negara anggota.

Ketika menggunakan RVC dalam penentuan asal barang, maka setiap anggota ASEAN didorong untuk memainkan peranannya sendiri sehingga memiliki comparative advantage. Penggunaan RVC ini juga berfungsi sebagai filter instrument barang-barang di luar komunitas ASEAN yang tidak dilengkapi dokumen $\mathrm{COO}$ yang jelas.

\section{- Teknologi Sistem Pendataan Ekspor Impor}

Sebagai ujung tombak Pemerintah

${ }^{29}$ Oliver Cadot, dkk, "Rules of Origin for Preferential Trading Arrangement - Implication for the ASEAN Free Trade of EU and NAFTA", World Bank Policy Research Working Paper 4016, September 2006. dalam menanggulangi illegal transhipment, Instansi Bea dan Cukai perlu dilengkapi dengan sarana dan prasarana memadai dan bebasis pada teknologi yang mumpuni karena disinilah celah pemalsuan dokumen COO terjadi dan berakibat maraknya penyelundupan melalui illegal transhipment. Permasalahan klasik mengenai teknologi dan infrastruktur merupakan suatu kebutuhan yang tidak dapat ditawar. Meningkatnya volume impor di Indonesia harus dilakukan pengecekan agar terhindar dari dumping, begitupula jika terjadi lonjakan ekspor harus diwaspadai karena akan berakibat pada tuduhan illegal transhipment dari negara tujuan.

\section{Rules of Origin Sebagai Instrument Penanganan Represif}

Sebagaimana telah dijabarkan dalam bab sebelumnya, salah satu tujuan penerapan Rules of Origin adalah sebagai ukuran untuk menerapkan tindakan dan instrumen kebijakan perdagangan seperti anti-dumping dan safeguard.

Suatu barang hasil illegal transhipment dapat dikategorikan sebagai barang hasil impor illegal apabila telah sampai di negara tujuan ekspor akan diperiksa oleh petugas Kepabeanan mengenai 2 hal , (1) apakah country of origin barang telah sesuai dan (2) apakah kode HS barang telah sesuai dengan yang tercantum dalam Rules of Origin dan dokumen lain yang disertakan. Jika tidak, maka barang akan dikategorikan sebagai barang impor ilegal dan dikenakan tarif bea masuk antidumping atau safeguard. 
Pada prinsipnya GATT hanya memperkenankan tindakan proteksi terhadap industri domestik melalui tarif (menaikkan tingkat tarif bea masuk) dan tidak melalui upaya - upaya perdagangan lainnya (nontarriff commercial measures). ${ }^{30}$ Perlindungan melalui tarif ini menunjukkan tingkat perlindungan yang diberikan dan masih terbukanya persaingan yang sehat dalam praktik perdagangan internasional. ${ }^{31}$

\section{Kesimpulan}

1. Pengaturan Rules of Origin diatur dalam Agreement on Rules of Origin dalam GATT dan Kyoto Konvention 1999 sebagai perjanjian multilateral serta implementasi di Indonesia terdapat dalam dalam UU No. 10 Tahun 1995 jo UU No. 17 Tahun 2006 tentang Kepabeanan. Namun, di dalam UU Kepabeanan tidak diatur secara spesifik mengenai jenis Rules of Origin yang dianut Indonesia padahal negara ini aktif turut serta dalam berbagai perjanjian Free Trade Agreement.

2. Untuk mengatasi adanya illegal transhipment dalam lalu lintas perdagangan internasional yang semakin intens, peranan Rules of Origin sebagai instrumen penanganan baik secara preventif maupun represif dapat dipandang sebagai suatu opsi perlindungan hukum bagi produsen dalam negeri.

${ }^{30}$ Barutu, Christophorus, "Ketentuan Antidumping, Subsidi, dan Tindakan Pengamanan (Safeguard) dalam GATT dan WTO”, PT Citra Aditya Bakti, Bandung, 2007.

${ }^{31}$ Ibid hal. 27.
3. Penanganan secara preventif meliputi optimalisasi ketentuan Rules of Origin Indonesia sebagai filter instrument dengan (1) memperketat proses verifikasi SKA, (2) pemberlakuan Regional Content Value sebesar 40\%, serta (3) peningkatkan teknologi sistem pendataan ekspor impor. Sedangkan penanganan secara represif merujuk pada pengenaan tarif berupa bea masuk anti-dumping atau bea masuk tindakan pengamanan untuk melindungi produsen domestik.

1. Indonesia di bawah Departemen Perdagangan harus memulai menyusun Rules of Origin sendiri secara spesifik dan tidak bergantung pada tawaran ketentuan asal barang dari partner perjanjian, mengingat Rules of Origin sangat diperlukan sebagai suatu identitas nasional bahwa suatu produk adalah buatan Indonesia.

2. Dalam UU Kepabeanan terdapat inkonsistensi penyebutan definisi sebagai penyelundupan atau pemindahkapalan yang memiliki makna yang berbeda seyogyanya diselaraskan.

3. Memperketat prosedur penerbitan COO serta pengawasan terhadap lalu lintas ekspor - impor khususnya terkait dengan isu illegal transhipment. 


\section{Daftar Bacaan}

\section{$\underline{\text { Buku }}$}

Barutu, Christophorus, "InstrumenInstrumen Hukum Kebijakan Perdagangan Internasional dan Kaitannya pada Certificate of Origin dalam Konteks Perdagangan Internasional", Buletin KPI Edisi-03/ KPI/2010, Jakarta, 2010.

"Ketentuan Antidumping, Subsidi, dan Tindakan Pengamanan (Safeguard) dalam GATT dan WTO”, PT Citra Aditya Bakti, Bandung, 2007.

LaNasa, Joseph A., "An Evaluation of the Uses and Importances of Rules of Origin, and the Effectiveness of the Uruguay Round's Agreement on Rules of Origin in Harmonizing and Regulating Them", 1995, diakses dari www.center.lae.nyu.edu.

Panduan Penerbitan Surat Keterangan Asal (Certificate of Origin) untuk Barang Ekspor Indonesia, "Ketentuan Penerbitan Certificate of Materials Imported from Japan," Direktorat Fasilitasi Ekspor dan Impor Direktorat Jenderal Perdagangan Luar Negeri Kementerian Perdagangan, 2010.

R. Winantyo dkk., "Masyarakat Ekonomi ASEAN (MEA) 2015 : Memperkuat Sinergi ASEAN di Tengah Kompetisi Global," PT. Elex Media Komputindo Kompas Gramedia, Jakarta 2008.

\section{$\underline{\text { TESIS }}$}

Supratignya, "Penentuan Country of Origin Marking dalam Kepabeanan di Indonesia”, Medan, 2005.

\section{JURNAL/ARTIKEL ONLINE}

Alan M. Steven dan Ed. Schmidgall Tellings, "Kamus Lengkap Indonesia Inggris," www.books.google.co.id., diakses pada 15 maret 2011.

"Coalition for Enforcement of AntiDumping and Countervailing Duties Orders," Members of US Manufacturing Industries, www.edwardhoward.com, diakses pada 3 Agustus 2011.

Departemen Perdagangan Republik Indonesia Direktorat Jenderal Perdagangan Luar negeri dan Direktoral Fasilitas Ekspor Impor, "Surat Keterangan Asal," www. skaservices.com, diakses pada 13 April 2011.

Guerin, Bill, "How to Beat US Trade Barriers," Southeast Asia, 22 Maret 2006, www.atime.com, diakses pada 5 April 2011.

“Instansi Penerbit SKA Jadi 85," 10 Juni 2010, diakses pada www.bataviase. co.id.

Jha, Sejuti, "Restrictive Rules of Origin and Their Circumvention: Studying Rules of Origin of the India-Sri Lanka Free Trade Agreement," South Asia Economic Jurnal II:I (2010).

Kawilarang, Rene A., "RI Serukan Penyeragaman Aturan di WTO," www.vivanews.com, diakses pada 17 Juni 2011.

Kinerja Pengamanan Perdagangan Tahun 2010 Meningkat Signifikan," Pusat Humas Kementerian Perdagangan Republik Indonesia, www.depdag. go.id. diakses pada 16 April 2011. 
Listyorini SR, "Menteri Perdagangan Marie Elka Pangestu : Kita Perangi Habis Illegal Transhipment," www. detiknews.com, diakses pada 3 April 2011.

Nurmayanti, "Ban Asal China dan India Makin Marak," www.tractor-truck. com, diakses pada 3 April 2011.

Oliver Cadot, dkk, "Rules of Origin for Preferential Trading Arrangement - Implication for the ASEAN Free Trade of EU and NAFTA," World bank Policy Research Working Paper 4016, September 2006.

Pamuji, Aris, "Certificate of Origin," www. certificate-of-origin.com, diakses pada 11 April 2011.

Raj Bhala 2, "International Trade Law Theory and Practice," (New York Lexis Publishing, 2001), hal. 459.

"Rules of Origin," www.indonesianmissioneu.org, diakses pada 4 Maret 2011.

Statement of Karl G. Glassman, Executive Vice President and Chief Operating Leggett \& Platt, Incorporated before the United States Senate Committee on Finance Subcommiittee on International Trade, Customs, and Global Competitiveness, "Enforcing America's Trade Laws in the Face of Customs Fraud and Duty Evassion," www.tradereform.org, diakses pada 15 Juni 2011.

"Verifikasi SKA Cegah Praktik Illegal Transhipment," www.bumn.go.id., diakses pada 15 Juni 2011.

"What is Transhipment?," Informed Trade International Import/Export, diakses dari www.itinl.com, www.wto.org, diakses pada 12 Maret 2011.

\section{PERUNDANG - UNDANGAN}

Agreement on implementation of Article IV of The General Agreement on Tariffs and Trade 1994, Annex to the Marakesh Agreement of 15 April 1994.

Agreement on Rules of Origin, Marakesh Protocol to the General Agreement on Tariffs and Trade 1994, disahkan tanggal 15 April 1994 di Marakesh, Maroko.

The International Convention on Simplification and Harmonization of Customs Procedures disepakati di Kyoto, Jepang tanggal 18 Mei 1973.

Undang-Undang Nomor 10 Tahun 1995 tentang Kepabeanan (Lembaran Negara Tahun 1995 Nomor 75, Tambahan Negara Tahun 1995 Nomor 3612) sebagaimana telah diubah dengan Undang-Undang Nomor 17 Tahun 2006 (Lembaran Negara Republik Indonesia Tahun 26 Nomor 93, Tambahan lembaran Negara Republik Indonesia Nomor 4661).

Peraturan Menteri Perdagangan Republik Indonesia Nomor 33/M-DAG/ PER/8/2010 tentang Surat Keterangan Asal (Certificate of Origin) untuk Barang Ekspor Indonesia.

Surat Edaran Direktur Jenderal Bea dan CUkai Nomor SE-05/BC/2010 tentang Petunjuk Pelaksanaan Penelitian Dokumen Pemberitahuan Impor Barang dalam Rangka Skema Free Trade Agreement.

\section{MAJALAH/SURAT KABAR}

"Pemerintah Waspadai Tuduhan Ekspor Sepatu ke Brazil," www. tempointeraktif.com, edisi Selasa 7 September 2010, diakses pada $25 \mathrm{Mei}$ 2011. 
Sa'aidah, Iffah, "Pembentukan Mekanisme Self Certification di ASEAN," edisi 56/KPI/2009, diakses pada www. ditjenkpi.depdag.go.id.

Warta Bea Cukai, "Krisis Ekonomi Global Picu Lonjakan Inisiasi Dumping," Edisi 418, September 2009. 
172 Yuridika: Volume 27 No 2, Mei-Agustus 2012 